\title{
Article \\ The Effect of Night Low Temperature on Agronomical Traits of Thirty-Nine Pepper Accessions (Capsicum annuum L.)
}

\author{
Sherzod Nigmatullayevich Rajametov $\left.{ }^{+} \mathbb{D}^{(}\right)$Kwanuk Lee ${ }^{+}(\mathbb{D}$, Hyo-Bong Jeong, Myeong-Cheoul Cho (D), \\ Chun-Woo Nam and Eun-Young Yang *
}

National Institute of Horticultural \& Herbal Science, Rural Development Administration, Wanju 55365, Korea; sherzod_2004@list.ru (S.N.R.); kwanuk01@korea.kr (K.L.); bong9846@korea.kr (H.-B.J.); chomc@korea.kr (M.-C.C.); cwsky1004@daum.net (C.-W.N.)

* Correspondence: yangyang2@korea.kr; Tel.: +82-(0)63-238-6613; Fax: +82-(0)63-238-6605

+ Equal contribution.

check for

updates

Citation: Rajametov, S.N.; Lee, K.; Jeong, H.-B.; Cho, M.-C.; Nam, C.-W.; Yang, E.-Y. The Effect of Night Low Temperature on Agronomical Traits of Thirty-Nine Pepper Accessions (Capsicum annuum L.). Agronomy 2021, 11, 1986. https://doi.org/10.3390/ agronomy11101986

Academic Editor: Santiago Signorelli

Received: 3 September 2021

Accepted: 29 September 2021

Published: 30 September 2021

Publisher's Note: MDPI stays neutral with regard to jurisdictional claims in published maps and institutional affiliations.

Copyright: (c) 2021 by the authors. Licensee MDPI, Basel, Switzerland. This article is an open access article distributed under the terms and conditions of the Creative Commons Attribution (CC BY) license (https:// creativecommons.org/licenses/by/ $4.0 /)$.

\begin{abstract}
Pepper plants are subject to complex environmental factors including abiotic and biotic stresses in fields, as well as the significant effects of climate changes, including low and high temperatures. Low temperature stress in the growth and development of pepper plants is one of the most critical issues, and directly impacts the crop yield and productivity of pepper plants. Therefore, it is essential to select and breed low temperature-(LT) tolerant pepper (Capsicum annuum L.) cultivars. This research was conducted to assess the agronomical traits of 39 pepper accessions belonging to the chili and bell fruit varieties which were cultivated under two different night temperature set-points: at $15{ }^{\circ} \mathrm{C}$ for a suboptimal temperature (CT) and at $10{ }^{\circ} \mathrm{C}$ for a low temperature (LT). The plant heights (PH) of most pepper accessions in a LT were significantly decreased compared to those in a CT. The stem diameter (SD) and the length of main axis (LMA) varied depending on the genotypes under LT. Moreover, the number of flowers (NFL), total number of fruits (NFR), fruit yield (FY), fruit fresh weight (FFW), fruit length (FL), fruit diameter (FD), and number of seeds in a fruit (NSF) remarkably declined in a LT compared to in a CT. The evaluated agronomical traits between LT and CT were further applied for the correlation analysis, principal component analysis (PCA), and hierarchical cluster analysis. Notably, the FY trait was correlated with other reproductive traits including NFR, FFW, FD, and FL on the positive directions and thirty-nine LT-treated pepper accessions were clustered into seven groups by the hierarchical clustering analysis. The selected accessions were primarily involved in the positive trends with the reproductive index including NFR, FL, FD, and FFW traits and could be used for pepper breeding programs to develop LT-tolerant cultivars.
\end{abstract}

Keywords: chili and bell pepper; low temperature stress; vegetative and reproductive traits; pepper breeding; PCA; hierarchical cluster analysis

\section{Introduction}

Pepper plants (Capsicum annuum L.) originate from the American tropics, are classified into the Solanaceae family, and are considered as an essential horticultural crop. Among the 30 species in Capsicum, around five species, including C. annum, C. baccatum, C. chinense, C. frutescens mill, and C. pubescens, are broadly domesticated by plant breeders and farmed in agricultural areas [1]. The pepper fruits of chili and bell peppers are used in diverse cuisines as a source of basic ingredients, contributing a variety of vitamins, phytochemicals, minerals, food colors, and capsaicin [2-4]. The importance of peppers in agriculture and the cultivation area and production of peppers is increasingly worldwide. According to the Food and Agriculture Organization (FAO) and the Korean Statistical Information Service (KOSIS) in 2019, the cultivation area and the production of peppers accounted for approximately 4.5 million ha and 61 million tonnes of the total green and dried peppers grown worldwide (http:/ / www.fao.org/faostat/), as well as around 36,600 ha and 334,280 tonnes 
of green and dried peppers of both chili and bell varieties in Korea (https:/ / kosis.kr/eng (accessed on 9 August 2021), respectively.

Climate changes, including low and high temperatures, strong wind, drought, flooding, and heavy rainfall can severely influence crop yield and productivity [2,5]. Particularly, reports demonstrated the impact of the night low temperature (NLT) with different temperature regimes during the period of entire growth and development $[6,7]$. The NLT remarkably affected seed germination, seedling growth, leaf morphology, stem diameter (SD), and plant height (PH) during the vegetative stages of tomato, cucumber, and pepper plants [7-14], causing poor growth and development. The temperature stress also affected the reproductive index, including the agronomical traits of the number of flowers (NFL), the number of fruits (NFR), fruit set (FS), and fruit yield (FY) during reproductive stages of pepper plants [15-17]. Since the flower development was highly associated with NFR, FS, and FY in response to LT, many studies focused on the development of the floral organs. For example, the plants grown in temperatures below $15^{\circ} \mathrm{C}$ resulted in abnormal flower shapes, reduced pollen activity and quality [18-20], parthenocarpic fruits [21], a decrease in the number of seeds in the fruit (NSF) [21-23]. Moreover, in comparison with those grown in normal and low temperatures, flower development was shown in the malformation of unexpanded petals, stunted stamens containing a few of pollen, and a reduced pollen germination activity in androecium [19,22]. Flower development was also impaired by the swollen ovary and shorter styles in the gynoecium, resulting in the poor quality of fruit development; small, flat, and irregular shaped fruits [15-22]. Although the effects of NLT on the aforementioned vegetative and reproductive parameters were determined in pepper plants, the impact of NLT was only characterized in limited accessions and mainly in sweet peppers.

The temperature regulation is one of the most important factors for pepper growth and is preferentially considered for cultivation in a winter greenhouse. According to the Korea Meteorological Administration (KMA) (https:/ / www.weather.go.kr/w/index.do (accessed on 9 August 2021)) and our previous publication [19], in Wanju, where this study was performed in Korea, the minimum and maximum temperatures fluctuated from -6.3 to $8.7^{\circ} \mathrm{C}$. Additionally, the average temperature was maintained from -1.7 to $3.9^{\circ} \mathrm{C}$ for the winter season, as has been the case since 1970, indicating that the climate of Wanju fluctuated from -7 to $10{ }^{\circ} \mathrm{C}$ during the period of winter season. Generally, the heating demand for greenhouse cultivation significantly increased at night time in winter [24] and the heating accounted for around $19-23 \%$ of the operating costs in Korea from 2017-2019 [25]. Several studies showed that sub-optimal temperatures in greenhouses could decrease energy costs by approximately $16 \%$ with a $2{ }^{\circ} \mathrm{C}$ temperature reduction [26], suggesting that the sub-optimal temperature ranging from $15-20^{\circ} \mathrm{C}$ could be considered as the minimal low temperature, which avoided serious damage to plant growth and development [27,28]. Interestingly, it was shown that LT led to a higher fruit yield than the optimal temperature $\left(>20^{\circ} \mathrm{C}\right)$ [22], whereas LT $\left(<10^{\circ} \mathrm{C}\right)$ resulted in the severe defective growth and development of the plants $[29,30]$. However, a few studies recently elucidated the development of breeding systems for selecting low temperature (LT)-tolerant pepper accessions. There is still a possibility of developing breeding programs with a large number of different fruit types for pepper plants, economically regulating NLT at $10^{\circ} \mathrm{C}$ with the optimal temperature set-points at $15-20^{\circ} \mathrm{C}$ in winter greenhouse.

In this work, we analyzed the agronomical traits of the pepper plants, including chili peppers $(n=27)$ and bell peppers $(n=12)$, in response to night low temperatures in greenhouse conditions. The vegetative parameters of $\mathrm{PH}, \mathrm{SD}$, and LMA and the reproductive parameters of NFL, FY, FW, FD, NFR, and NSF were investigated among 39 pepper genotypes between $15^{\circ} \mathrm{C}$ and $10^{\circ} \mathrm{C}$ in a greenhouse. On the basis of this correlation, as well as PCA and cluster analysis, together with ten agronomical traits, we selected four genotypes of chili peppers and four genotypes of bell peppers exhibiting low or high performances of vegetative and reproductive parameters, which were associated with high FY traits between LT and CT. The characterized and identified pepper genotypes in the present 
study will be used as a good resource for pepper breeders to breed LT stress-tolerant cultivars in winter greenhouses, with the consideration of a high FY index.

\section{Materials and Methods}

\subsection{Plant Material and Growth Conditions}

A total of 39 pepper breeding lines including chili $(n=27)$ and bell peppers $(n=12)$ from National Institute of Horticultural and Herbal Science (NIHHS, Korea, $35^{\circ} 83^{\prime} \mathrm{N}$, $127^{\circ} 03^{\prime} \mathrm{E}$ ) were utilized in the experiments (Table S1). The seeds of the 39 pepper lines were sown on 28 September 2020 in plastic trays which were $52 \mathrm{~cm} \times 26 \mathrm{~cm}$ in pot size and $6 \mathrm{~cm} \times 6 \mathrm{~cm}$ in cell size. The trays were transferred into a glasshouse that maintained $26 / 18{ }^{\circ} \mathrm{C}$ (day/night) and relative humidity from $65-70 \%$ and given one liter of water, daily. 14-day-old seedlings were transplanted on 13 November 2020 into two plastic film greenhouses. Pepper seedlings of ten plants per accession were planted with a distance of $1.5 \mathrm{~m} \times 35 \mathrm{~cm}$ between plants in both LT and CT greenhouses. To help the pepper seedlings adapt new environment conditions, night temperature set-point was initially maintained at $15{ }^{\circ} \mathrm{C}$ for 2 weeks in both greenhouses and then was modulated for LT and $\mathrm{CT}$, respectively.

\subsection{Soil Preparations}

The soil preparations in the trays and two greenhouses were completed as previously described in [16]. The commercial media (Bio Sangto, Seoul, Korea) which consisted of coco peat $(47.2 \%)$, peat moss $(35 \%)$, zeolite $(7 \%)$, vermiculite $(10.0 \%)$, dolomite $(0.6 \%)$, humectant $(0.006 \%)$, and fertilizers $(0.194 \%)$, which were made of $270 \mathrm{mg} \mathrm{kg}^{-1} \mathrm{of} \mathrm{N}, \mathrm{P}$ and $\mathrm{K}$, respectively. The soil preparations in two greenhouses were prepared, following the recommendations of the Korea Soil Information System (KSIS) (https:/ / soil.rda.go.kr (accessed on 28 August 2021)), equally with pre-plant broadcast manure at a dose of $1 \mathrm{~kg} \mathrm{~m}^{-2}$ and basal fertilizer containing $16 \mathrm{~g} \mathrm{~m}^{-2} \mathrm{~N}, 8 \mathrm{~g} \mathrm{~m}^{-2} \mathrm{~K}_{2} \mathrm{O}$, and $16 \mathrm{~g} \mathrm{~m}^{-2} \mathrm{P}_{2} \mathrm{O}_{5}$, which was regularly fertigated with the mixture of solution A (5.5\% nitrogen, $4.5 \%$ potassium, $4.5 \%$ calcium, $0.00014 \%$ boron, $0.05 \%$ iron, $0.0001 \%$ zinc, and $0.0002 \%$ molybdenum) and $\mathrm{B}(6 \%$ nitrogen, $2 \%$ phosphorus, $4 \%$ potassium, $1 \%$ magnesium, $0.05 \%$ boron, $0.01 \%$ manganese, $0.005 \%$ zinc, and $0.0015 \%$ copper) in 1200 L water (Mulpure, Daeyu Co., Ltd., Gyeongsan, Korea).

\subsection{Temperature Regulations}

The winter climate where this experiment was conducted was shown in our previous report [16]. Briefly, the temperature was monitored and recorded in LT and CT greenhouses during the period of the pepper cultivation using data logger (Figure S1) (WatchDog 1450, Spectrum Technologies Inc., Aurora, IL, USA). Nighttime temperature was maintained by heating machine (Model TKP-800, Tae Kwang Machine Co., LTD., Daegu, Korea) whenever the temperature decreased below the $10{ }^{\circ} \mathrm{C}$ and $15{ }^{\circ} \mathrm{C}$ set-points. The relative humidity (RH) was kept within approximately $40-60 \%$ in both greenhouses, respectively.

\subsection{Diseases and Pest Controls}

Diseases and pest controls were conducted as previously described in [16]. Briefly, $20 \%$ of Spiromesifen (Farmhannong, Seoul, Korea) was diluted with the ratio of 1:2000 for controlling whitefly; 5\% of Rampage (Hankooksamgong, Seoul, Korea) was diluted with the ratio of 1:1000 for controlling thrips. In addition to this, 30\% of Iminoctadine tris (Farmhannong, Seoul, Korea) was diluted with the ratio of 1:1000 for controlling leaf and gray molds; 50\% of Polyoxin B (Farmhannong, Seoul, Korea) was diluted with 1 to 5000 for controlling powdery mildew and fungi.

\subsection{Data Collections}

The pepper accessions were planted with the same arrangement in LT and CT greenhouses from three independent biological plants, which were randomly selected among ten 
plants for measurement the reproductive parameters. The number of flowers (NFL) was determined from the second to fifth internodes and the vegetative parameters, including plant height $(\mathrm{PH})$, stem diameter (SD), and length of main axis (LMA), were measured at 120 days after transplanting (DAT) of seedlings. Total number of fruits per plant (NFR) and fruit yield per plant (FY) were measured from three individual plants, randomly. Five fruits of each accession were collected for measurement of fruit fresh weight (FFW), fruit length (FL), fruit diameter (FD), and the number of seeds in a fruit (NSF) using a digital electron Micro Weighing Scale MW-II (CAS), a ruler, and a caliper, respectively.

\subsection{Data Analysis}

The significant difference in vegetative parameters of $\mathrm{PH}, \mathrm{SD}$, and LMA, and reproductive parameters of NFL, NFR, FY, FD, FL, FFW and NSF were assessed as described in the figure legends with Student's t-test using EXCEL 2016 software (Microsoft Co., Ltd., Albuquerque, NM, USA). To figure out the effects of LT on the evaluated traits, the score of agnomical traits was calculated by dividing LT by CT and multiplying by $100(\%)$. The analysis of correlation coefficients was performed among the total populations $(n=39)$ using EXCEL 2016 (Microsoft, Redmond, WA, USA). The multivariate analysis, including correlation analysis, principal components analysis (PCA), and hierarchical cluster analysis were assessed using SPSS program (IBM SPSS v27.0, Chicago, IL, USA). The adequacy of the samples was carried out by the Kasier-Meyer-Olkin $(\mathrm{KMO}>0.5)$, and Bartlett's test of Sphericity (BTS $<0.001$ ) was utilized as an indicator in the proper construct of the PCA model to evaluate the relationship between variables.

\section{Results}

\subsection{The Vegetative Traits with Chili and Bell Peppers}

In order to understand the response of pepper plants to the night low temperature (NLT), the vegetative parameters including $\mathrm{PH}, \mathrm{SD}$, and LMA were investigated among 39 pepper accessions at $120 \mathrm{DAT}$ in LT and CT greenhouses. The growth rate of most of the accessions in PH significantly reduced in LT compared to that in CT (Figure 1A). Only one accession C22 of chili pepper was observed with no significant difference in both LT and CT. The lowest significant difference $(p \leq 0.05)$ was identified in C17 of chili pepper and P06 of bell pepper.

Next, in order to evaluate the effect of LT on the stem growth, the plant stem diameter (SD) was measured among 39 pepper accessions. Sixteen accessions of chili pepper and seven accessions of bell pepper were observed to have no significant difference between LT and CT (Figure 1B). The significant differences $(p \leq 0.01)$ were identified with C02, C05, $\mathrm{C} 17$, and C20 of chili peppers and P01 of bell pepper. Interestingly, the SD of C05 accession was higher in LT than in CT. In addition to this, the growth of LMA was investigated and thirteen accessions of chili peppers and two accessions of bell peppers were observed with no remarkable differences between LT and CT (Figure 1C). The significant difference $(p \leq 0.001)$ was determined in C13, C16, C21, and C23 of chili peppers and P01 and P02 of bell peppers. Taken together, the observations indicated that the effect of LT on vegetative traits was widely varied from genotypes among 39 pepper accessions. 


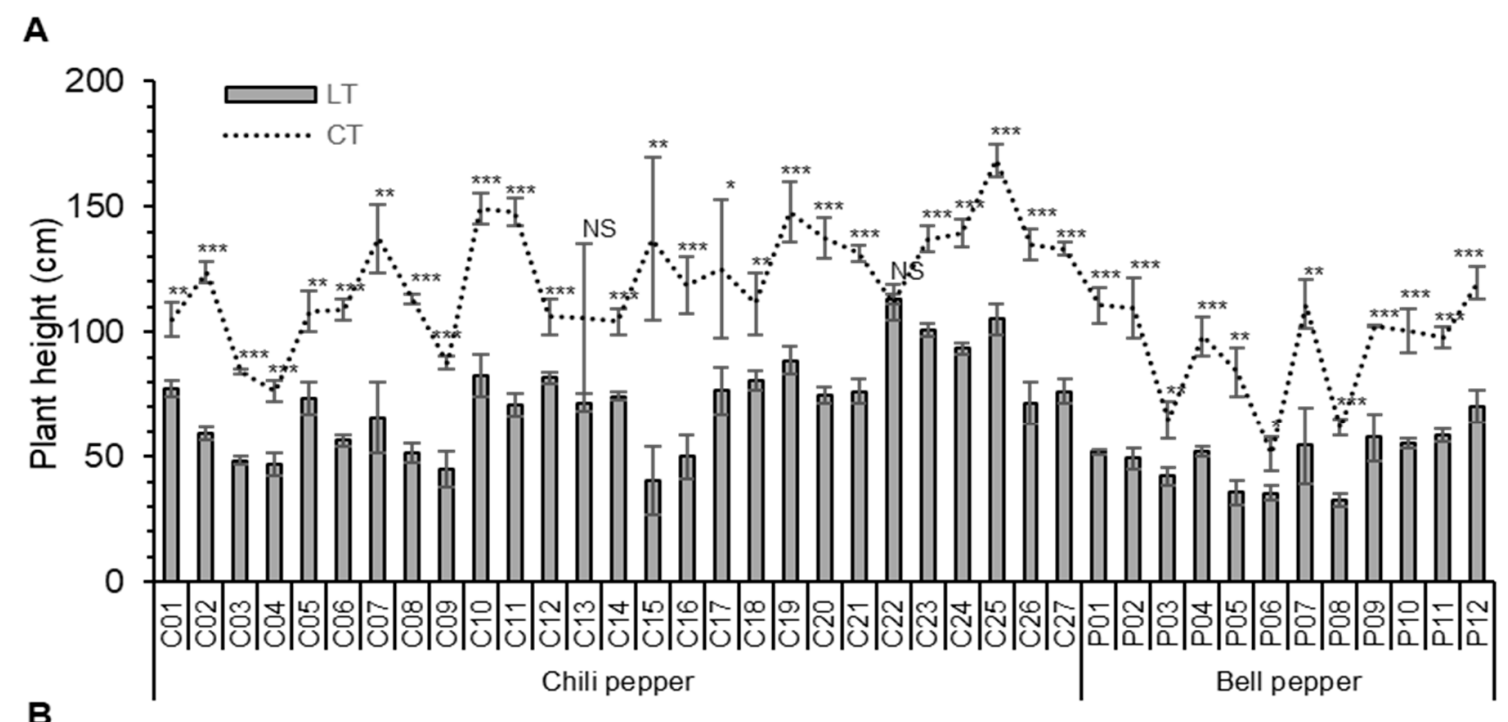

B
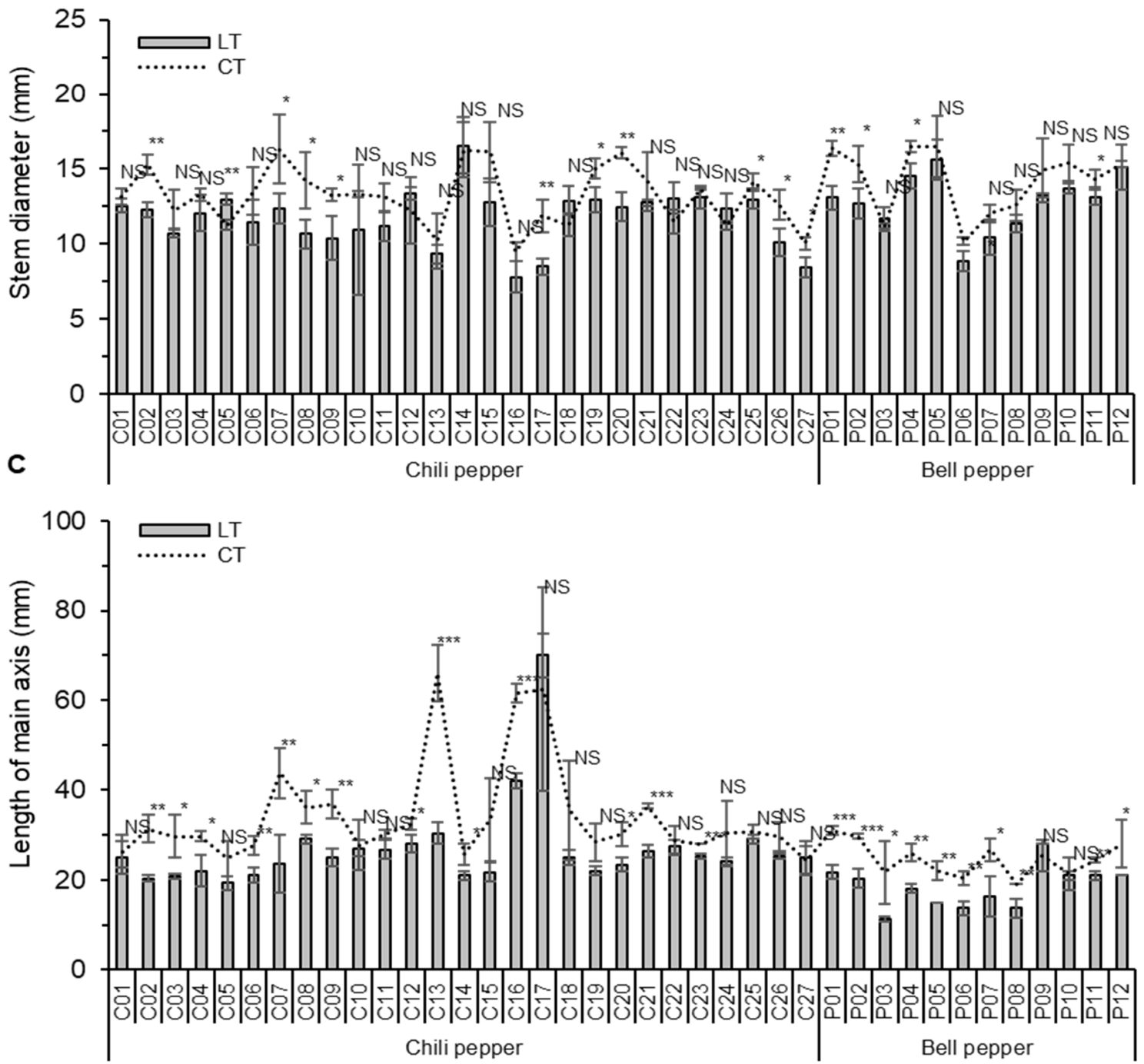

Figure 1. The evaluation of vegetative traits on (A) plant height, $(\mathbf{B})$ plant stem diameter, and $(\mathbf{C})$ length of main axis among 39 pepper accessions in LT and CT greenhouses. Plant height, stem diameter, and length of main axis were measured at 120 days after transplanting. Significant differences were evaluated with Student's $t$-test with $p \leq 0.05, p \leq 0.01$, and $p \leq 0.001$ and denoted by ${ }^{*}, * *$ and ${ }^{* * *}$, respectively. NS means not significant and bars indicate \pm standard deviation $(n=3)$. 


\subsection{The Reproductive Traits of NFL, NFR, and FY with Chili and Bell Peppers}

In order to determine the response of pepper accessions to NLT regarding the reproductive traits, the reproductive parameters including NFL, NFR, and FY were investigated among 39 pepper accessions at 120 DAT in LT and CT greenhouses. The effect of LT on NFL was different depending on the pepper accessions (Figure 2A). The floral organs were not developed in C04, C13, and C16 accessions in both LT and CT conditions, and the flowers of C03, C17, and P11 were developed in CT but not in LT. No significant difference in NFL was observed except for the P06 and P10 accessions between both LT and CT. In addition, the effect of LT on NFR per plant at 120 DAT was subsequently evaluated and observed in the significant reduction in most pepper accessions in LT (Figure 2B). Notably, C04, C08, C13, and C16 of chili peppers were not shown in any fruit in both LT and CT, whereas C22, P08, and P09 were not different between LT and CT. Because high fruit yield was one of the most important parameters to determine LT-tolerant pepper cultivars in breeding programs, the evaluation of $\mathrm{FY}$ was implemented and it was drastically decreased in LT compared to CT, except for P08 and P09 of bell peppers (Figure 2C). Interestingly, the highest index of FY over $500 \mathrm{~g}$ was identified in $\mathrm{C} 01, \mathrm{C} 02, \mathrm{C} 05, \mathrm{C} 18, \mathrm{C} 19, \mathrm{C} 23$, and $\mathrm{C} 24$ of chili peppers and in P01, P02, P03, and P04 of bell peppers in CT, whereas it was observed in C22 (226.7 g) of chili pepper and P04 (215.0 g) of bell pepper in LT.

\subsection{The Fruit Traits of FD, FL, FFW, and NSF with Chili and Bell Peppers}

In order to explore the impact of fruit traits in response to LT, the fruit traits-related FD, FL, FFW, and NSF were evaluated among 39 pepper accessions at 120 DAT in LT and $\mathrm{CT}$ greenhouses. FD dramatically decreased in most pepper accessions in LT in comparison with CT (Figure 3A). However, no appreciable difference in FD was found in C23 of chili peppers and P01 and P04 of bell peppers between LT and CT. In detail, the widest FD over $25 \mathrm{~mm}$ and $60 \mathrm{~mm}$ was found in C02, C05, C14, C15, C21, and C22 of chili peppers and P02, P03, P5, and P10 of bell peppers in CT, respectively. The widest FD over $15 \mathrm{~mm}$ and $50 \mathrm{~mm}$ was observed in C02, C05, C14, C22, and C23 accessions, and in P01, P02, P05, P08, and P09 accessions in LT.

A previous study reported that FD was highly associated with FL [31,32]. In order to validate the effect of LT on FL, together with FD, FL was measured among 39 pepper accessions and FL was noticeably reduced in most pepper genotypes in LT compared to CT (Figure 3B). However, no appreciable difference in FL was observed in P06 and P08 of bell peppers between LT and CT. In detail, the longest FL over $15 \mathrm{~cm}$ and $10 \mathrm{~cm}$ in CT was determined in $\mathrm{C} 02, \mathrm{C} 05, \mathrm{C} 06, \mathrm{C} 14, \mathrm{C} 18, \mathrm{C} 19, \mathrm{C} 22, \mathrm{C} 23$, and $\mathrm{C} 24$ of chili peppers, and in P01 and P02 of bell peppers. Moreover, the longest FL over $10 \mathrm{~cm}$ and $5 \mathrm{~cm}$ in LT was observed in C18, C19, C22, and C23 of chili peppers and P02, P04, and P09 of bell peppers, respectively. FFW was also investigated and decreased in most pepper accessions in LT compared to $\mathrm{CT}$, except for P08 and P09 of bell pepper which exhibited no significant difference between LT and CT conditions (Figure 3C). One study determined the effect of LT on the seed development in the pepper fruit, which caused the growth of seedless fruit (referred to as parthenocarphy) and a reduced fruit marketability [18]. To further confirm the effect of LT on seed development in a fruit, the number of seeds per fruit was counted. The results showed that NSF was reduced in a variety of pepper accessions and even all fruits of bell peppers did not develop any seeds in LT condition (Figure 3D). Intriguingly, the NSF of C12 accession increased in LT compared to CT and no appreciable difference in NSF was found in C25 and P05 accessions between LT and CT. In addition, the highest NSF over 80, 70, and 40 seeds in CT was identified in C20, C21, and C24 of chili peppers and P01, P02, and P09 of bell peppers and the highest NSF over 40 in LT was observed in C12, C24 and C25 of chili peppers. 


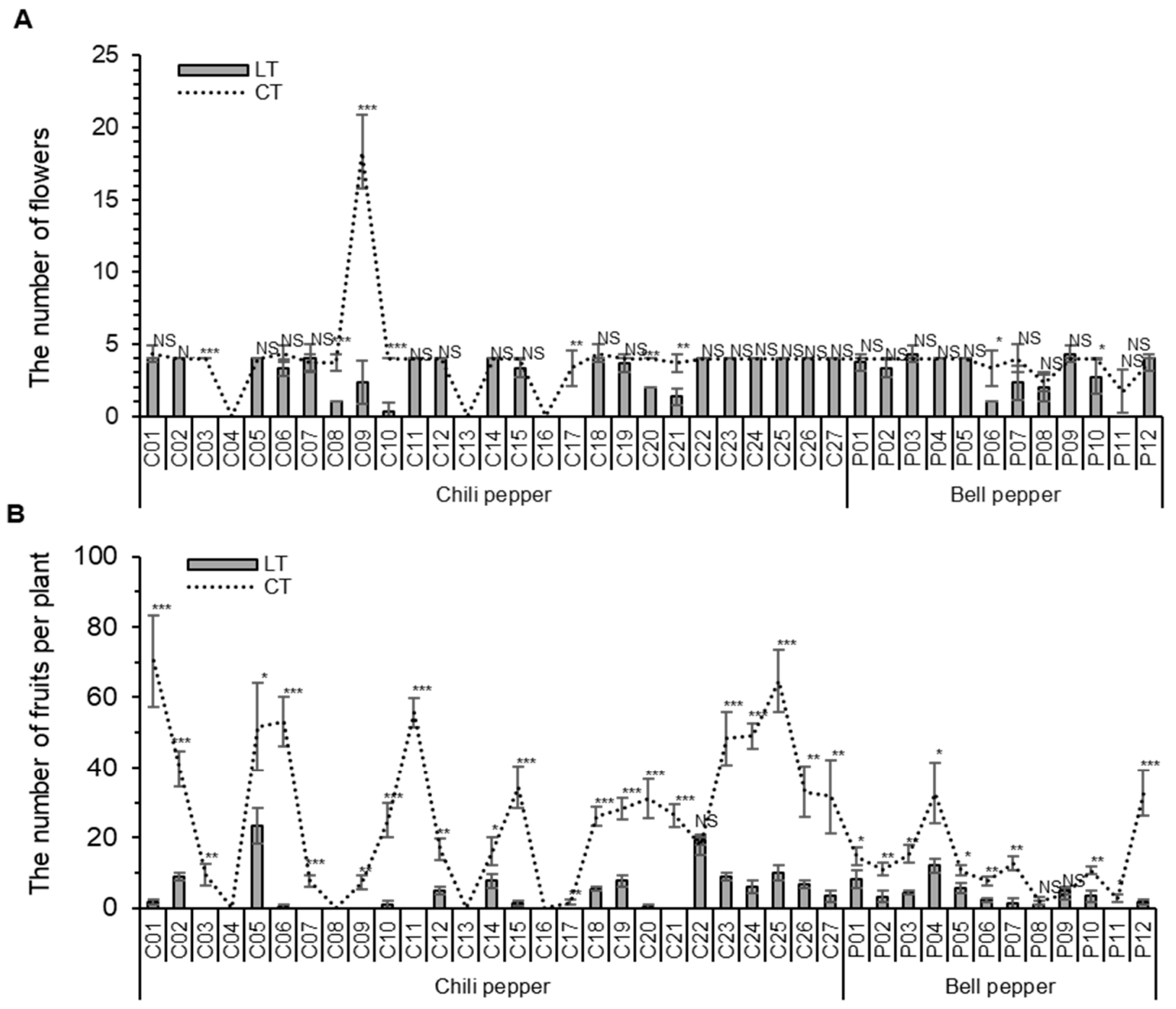

c

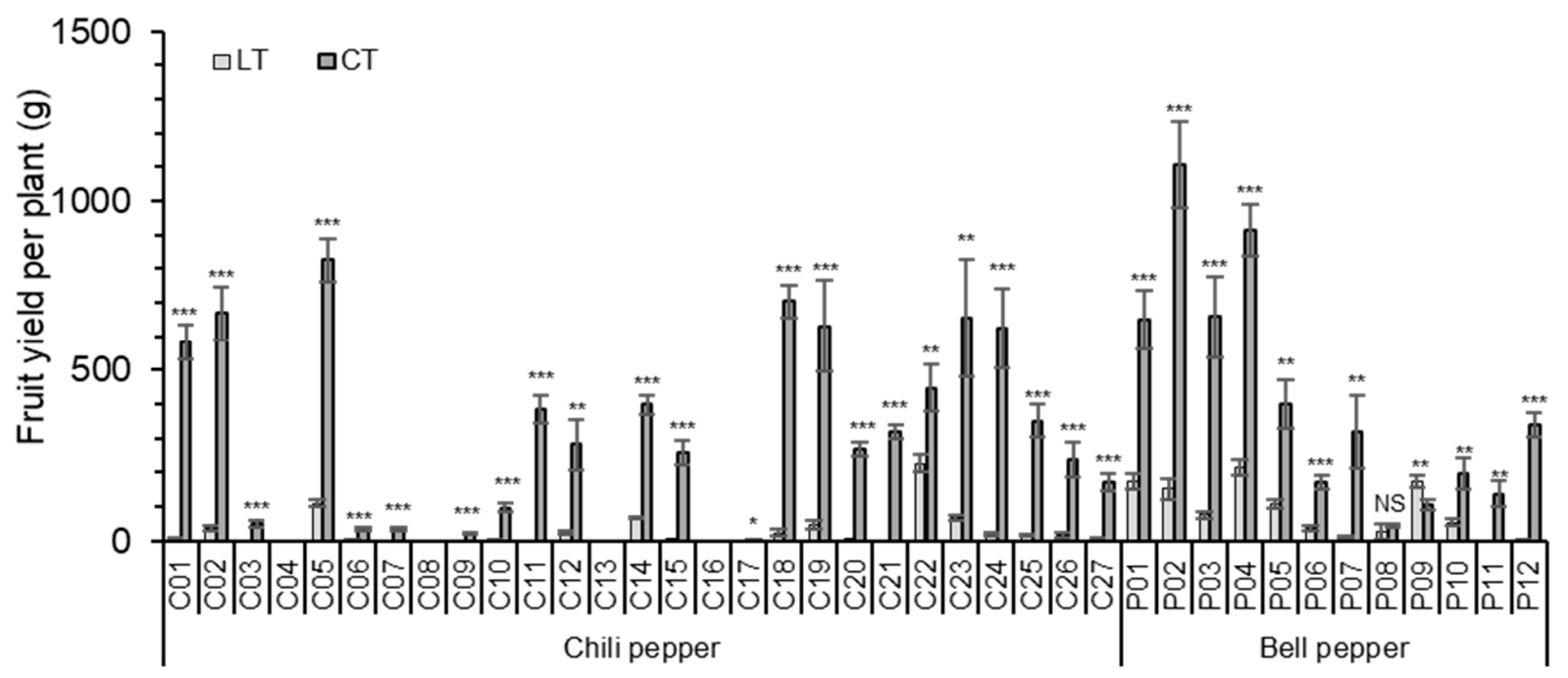

Figure 2. The evaluation of reproductive traits on (A) the number of flowers, (B) the number of fruits, and (C) fruit yield among 39 pepper accessions in LT and CT greenhouses. The reproductive parameters were measured at 120 days after transplanting. Significant differences were evaluated with Student's $t$-test with $p \leq 0.05, p \leq 0.01$, and $p \leq 0.001$ and denoted by ${ }^{* * *}$, and ${ }^{* * *}$, respectively. NS means not significant and bars indicate \pm standard deviation. $(n=3)$. 
A

B

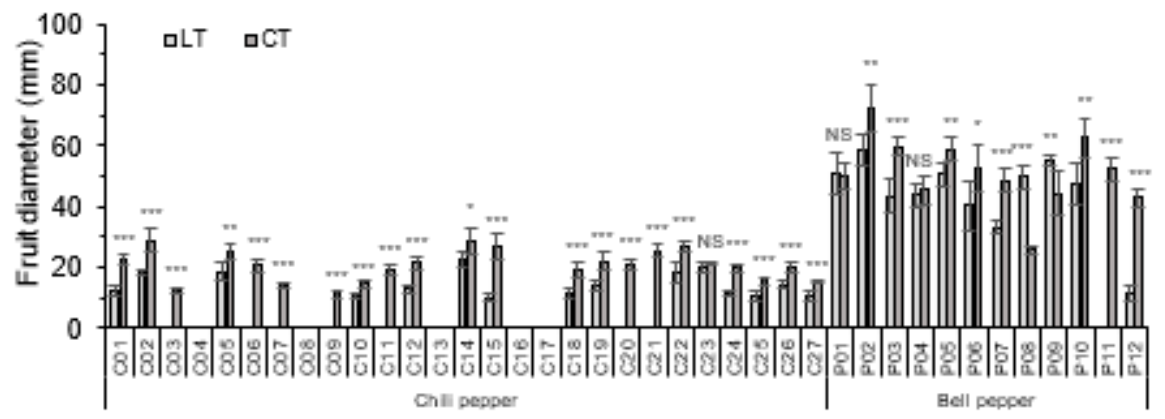

C
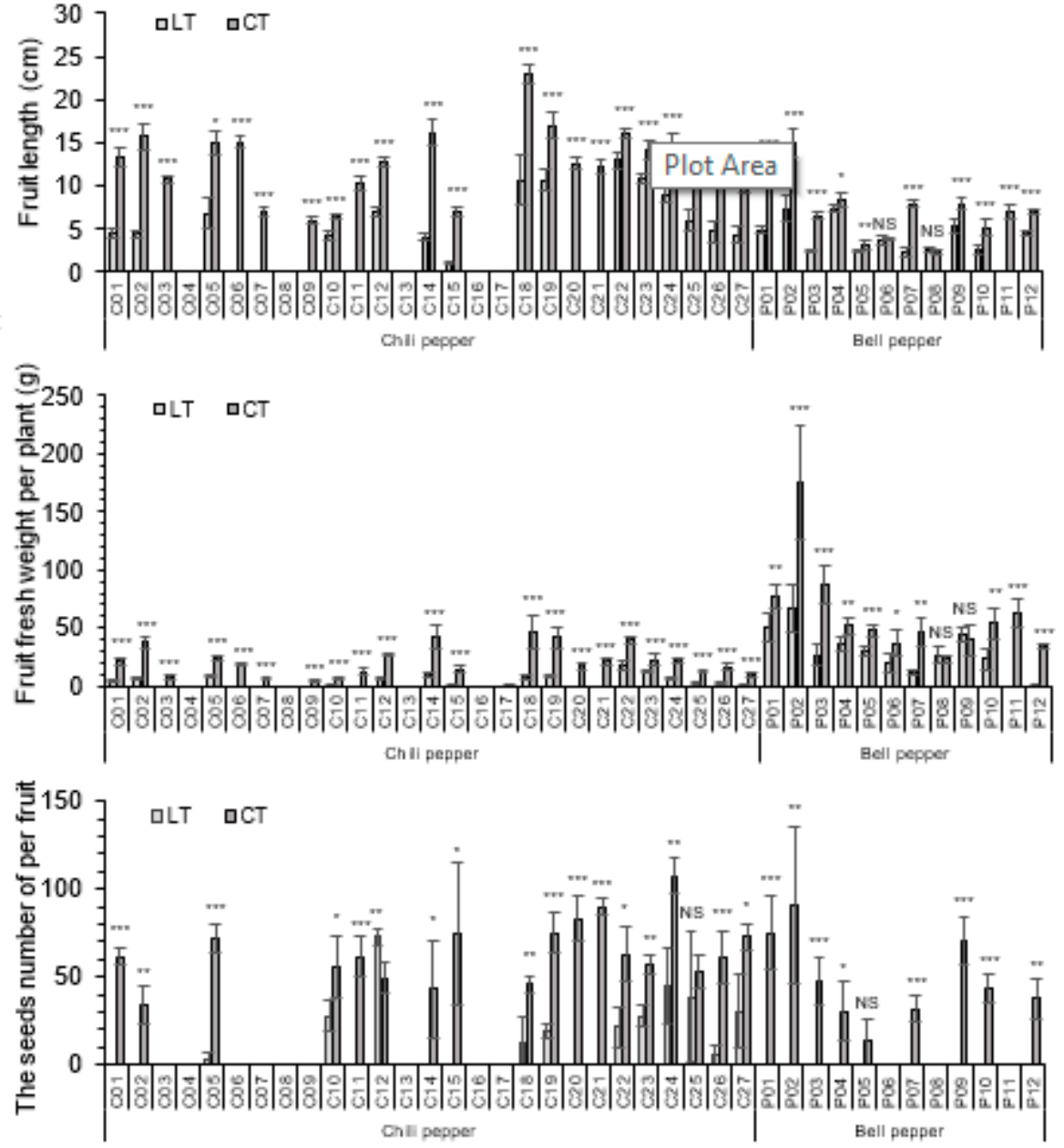

Figure 3. The evaluation of reproductive traits on (A) fruit diameter, $($ B) fruit length $(\mathrm{cm}),(\mathbf{C})$ fruit fresh weight, and (D) the number of seeds among 39 pepper accessions in LT and CT greenhouses. The reproductive parameters were measured at 120 days after transplanting. Significant differences were evaluated with Student's $t$-test with $p \leq 0.05, p \leq 0.01$, and $p \leq 0.001$ and denoted by ***, and $* * *$, respectively. NS means not significant and bars indicate \pm standard deviation $(n=3)$.

\subsection{The Principal Component Analysis (PCA) of Agronomical Traits}

In order to understand the relationship between the multiple variables, including the aforementioned parameters, a principal component analysis (PCA) was conducted (Figure 4). A correlation matrix of 10 variables was produced in LT and CT conditions (Figure S2). The Kaiser-Meyer-Olkin (KMO) was calculated for the adequacy of measured samples on vegetative and reproductive traits, and the score was 0.720. Bartlett's Test of Sphericity (BTS) was significantly lower than 0.001 , indicating that the samples and 
PCA construct were appropriate for PCA analysis. Five PCs were extracted from ten studied agronomical traits and the eigenvalues were greater than one from the first three (Table S2). To reduce the dimensions of the data space, the correlation matrix with the first two components of PCA was applied. The total variance of the acquired data was explained with the $65.76 \%$, which represented $46.63 \%$ from component factor 1 (PC1) and $19.13 \%$ from component factor 2 (PC2), respectively. The traits (scores $>0.30$ ) were loaded onto PC1 and PC2 (Table S2A). The first component PC1 contributed to multiple traits, concluding that FL had a major contribution towards positive loading vectors (0.885), followed by FD (0.878) and FW (0.791) within the first component, and PC2 exhibited FY (0.914) and NFR (0.815). This indicated that three major and two minor variables had a strong correlation with the first PC and second PC, respectively.

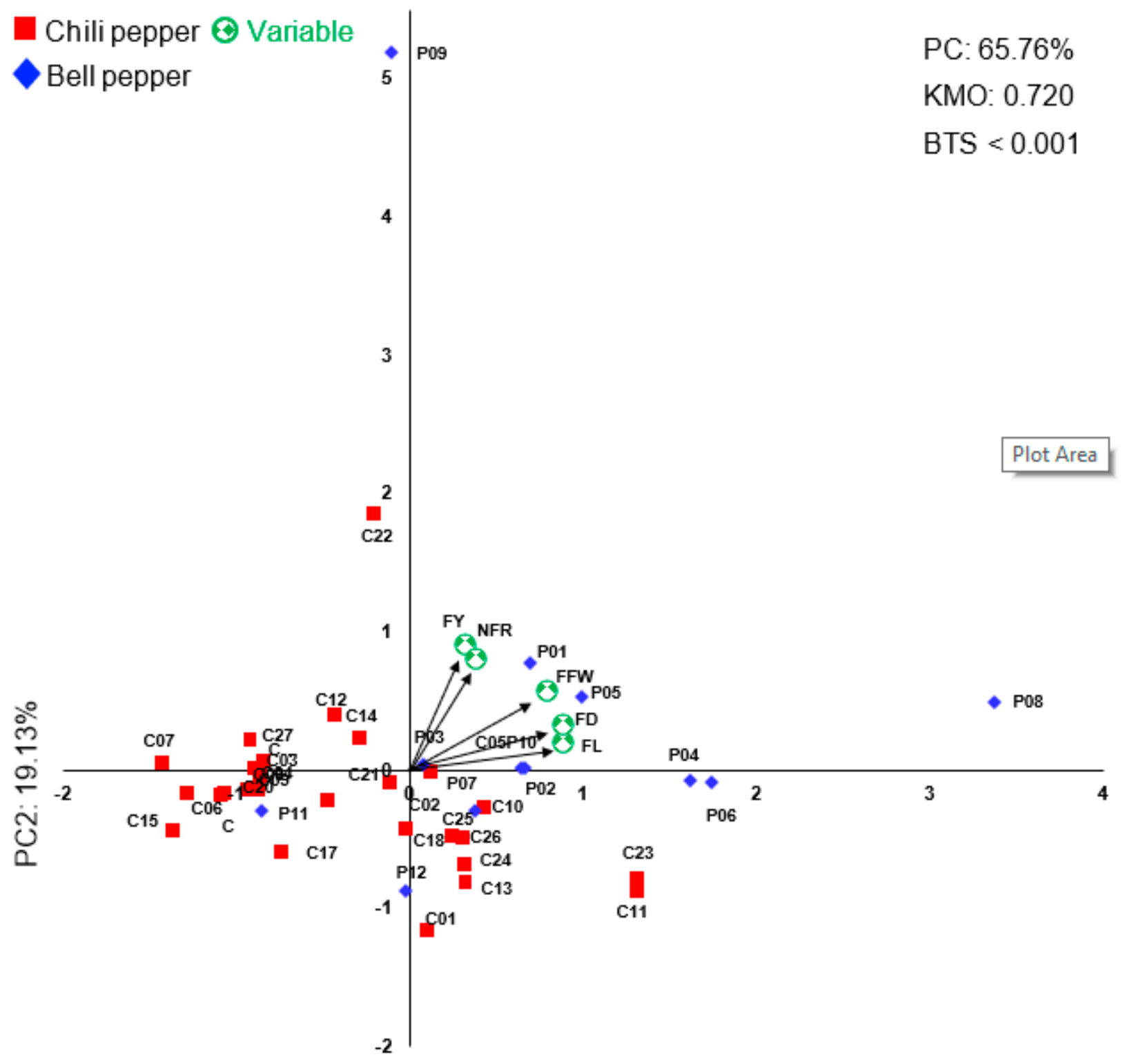

PC1: $46.63 \%$

Figure 4. Biplot for first two principal components was analyzed using the principal component analysis (PCA) for 10 agronomical traits among 39 pepper accessions possessing chili (red square) and bell (blue diamond) fruit varieties between LT and CT conditions. The green round circles with multiple diamonds and the arrows represent the variables and the direction of vectors, respectively. 


\subsection{Clustering Analysis}

In order to analyze the association with the PCs in 39 pepper accessions, a scatter plot matrix was drawn using the component factor 1 (PC1) and factor 2 (PC2), exhibiting no clear pattern for the grouping of pepper fruit varieties (Figure 4). The PC1 and PC2 factors were further justified to agglomerative hierarchical clustering utilizing the Euclidean distance matrix through Ward's method and the dendrogram was produced on the basis of the results. Seven major groups were distinctly clustered (Figure 5A). The results showed that group 1 primarily had a very low value of LMA and $\mathrm{PH}$; group 2 had a moderate low value of SD and NFL; group 3 had a low value of both vegetative and reproductive traits; and group 4 had a moderate value of SD in vegetative traits, and a high value of FL and FD in reproductive traits. Additionally, it displayed that the group 5 had a high value of $\mathrm{PH}$ and SD in vegetative traits and NFR and FL in reproductive traits; group 6 had a high value of FW, FL, and FD in reproductive traits; and group 7 had a high value of LMA in vegetative traits, and a high value of NFL, NFR, FY, FFW, and FD in reproductive traits. Depending on the clustering and the studied agronomical traits, the plants displaying a low performance of the agronomical traits were selected in two accessions (C01 and C02) of chili peppers and two accessions (P01 and P02) of bell peppers, and the plants showing a high performance of agronomical traits were selected in two accessions (C22 and C23) of chili peppers and two accessions (P08 and P09) of bell peppers (Figure 5B).

A

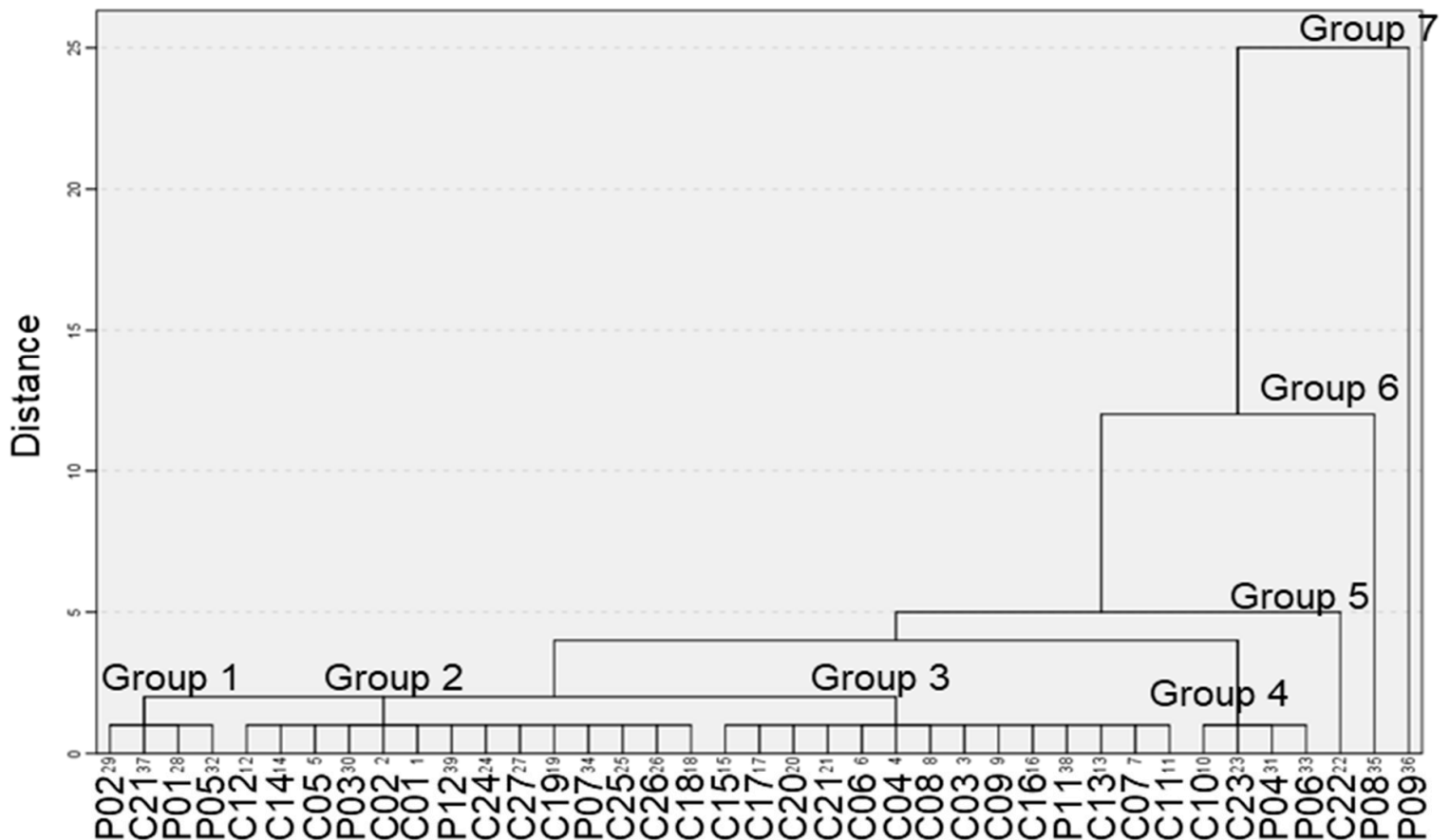

Figure 5. Cont. 


\section{B}
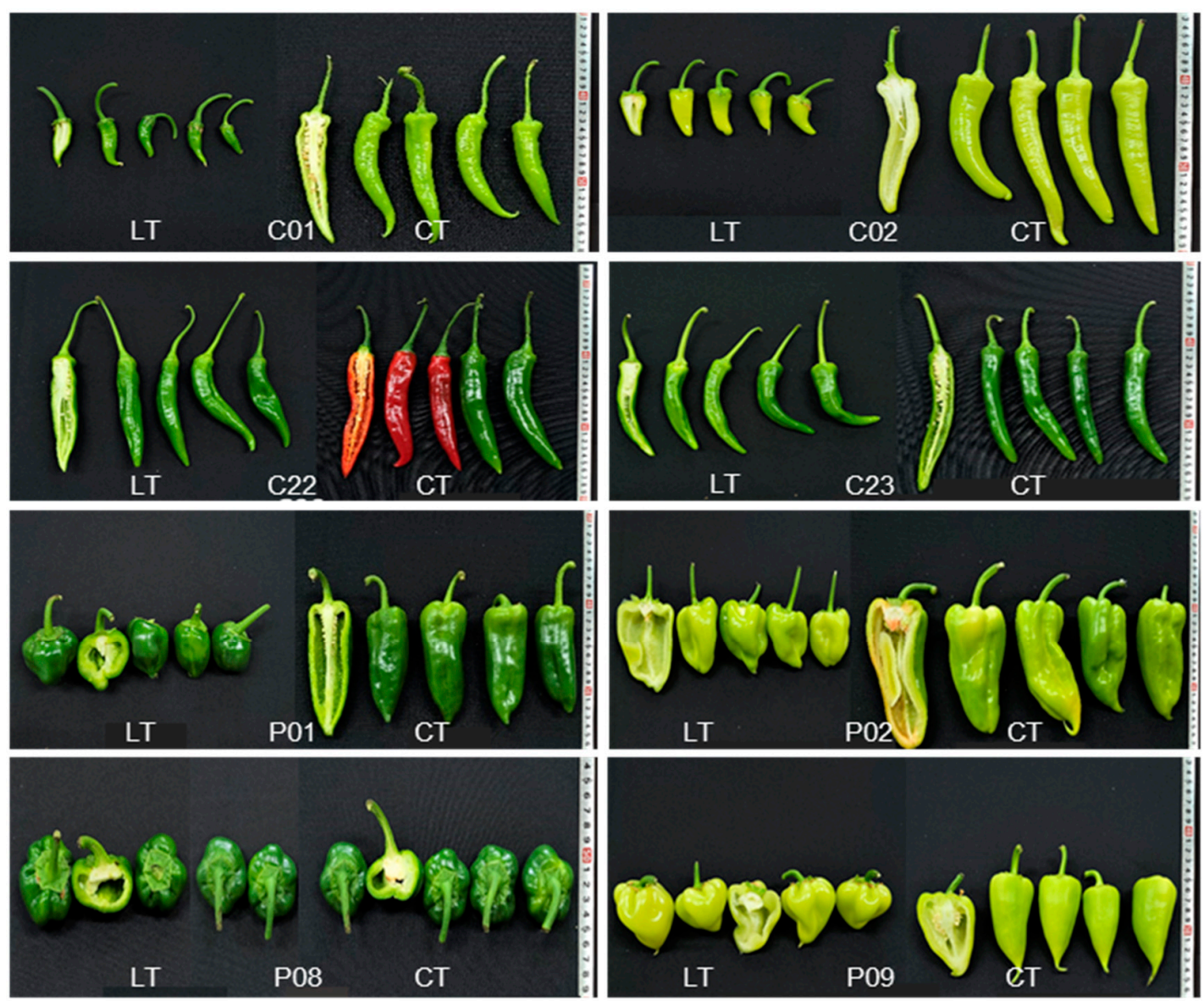

Figure 5. (A) Dendrogram was performed by the cluster analysis of 39 pepper accessions on the basis of the Euclidean distance using components factors 1 and factors 2. (B) Four pepper accessions in chili and bell pepper were selected and the pictures were shown in the fruits of pepper plants taken at 120 days between LT and CT greenhouse conditions.

\section{Discussion and Conclusions}

Pepper plants were naturally exposed to harsh cold stress during winter season in agriculture and possessed the cellular and molecular mechanisms to acclimate and overcome low temperature stress [33-36]. Previous reports demonstrated a response to LT with limited accessions, mainly in reproductive traits, including flower morphologies, fruit shapes, fruit varieties, and fruit yield $[6,18,19]$. Additionally, the effect of LT on the agronomical traits was determined primarily in sweet peppers. In this study, we assessed 39 pepper genotypes including chili $(n=27)$ and bell fruit varieties $(n=12)$ and evaluated the vegetative and reproductive traits during the entire period of the pepper growth and development stages under LT, which could economically reduce the heating demand of the pepper cultivation in a winter greenhouse.

The effect of LT showed that the PH decreased significantly in almost all accessions, except for one accession, C32, which was not significantly different among the chili peppers grown between the LT and CT greenhouses (Figure 1A). In line with our current results, previous studies determined that the effect of LT on PH influences the retarded growth of plant height in pepper and cucumber plants with different low temperature regimes [7,9,37]. In addition to this, previous studies also reported that the reduction in tomato plant height in LT could be correlated to the number of leaves, which influenced the relative growth rate and net assimilation rate with the modulated photosynthetic ability [9]. Next, it was in our interest to further investigate how the number of pepper leaves, leaf length, and leaf width, as well as the photosynthetic parameters were involved in PH in LT. 
The effect of LT on SD exhibited a reduction in twenty-one accessions (40.8\%) of chili peppers and five accessions (41.6\%) of bell peppers, respectively (Figure 1B), whereas other accessions in LT did not significantly decrease in SD, except for C05 which showed a higher growth of SD in LT than in CT. This result was in agreement with a previous study which determined the difference in the SD of tomato plants under LT $[15,16]$. The finding showed that the SDs varied depending on the tomato genotypes without fruit types [16]. Moreover, the effects of LT on LMA displayed a reduction in 13 accessions (48.2\%) of chili peppers and 10 accessions (83.3\%) of bell peppers, respectively (Figure 1C), indicating that the effect of LT on SD and LMA might be also significant among pepper genotypes, irrelevant of fruit types (Figure 1), and that the bell peppers would be very sensitive to LT in the vegetative traits compared to those in $\mathrm{CT}$, as previous studies mentioned [18]. In the current study, the positive high temperature (day temperature-night temperature $>0$ ) in tomato plants led to an increased stem thickness and enlogation, as well as the number of xylem vessels via the modulation of genes involved in the cell wall, GA, and auxin biosynthesis [38]. Furthermore, our studies were essential to provide factors affecting the pepper stem diameter and enlogation with the phytohormones under diverse LT regimes. Collectively, we did not completely understand how LT affected the vegetative index, such as SD and LMA, in pepper plants. Nevertheless, our current results clearly suggested that LT influenced pepper growth and development during the vegetative stages.

We conducted the investigation of a reproductive index including NFL, NFR, and FY. A study reported that NFL, in the first truss of the tomato plant, displayed no significant difference under a low temperature in the atmosphere, while the NFL was promoted by a low temperature in the root area [39]. In addition, our previous research found that the LT did not affect the NFL of the tomato plant and LT influenced the NFL with a genotypespecific interaction $[15,16]$. In the agreement with our previous studies, our current finding also showed that the NFL of most pepper accessions showed no remarkable difference between the LT and CT, although NFL was reduced in several accessions of chili and bell peppers (Figure 2). Despite that, we did not understand why the effect of LT on NFL in most accessions was not influenced. Our further studies need to focus on elucidating the mechanistic role of the impact of LT on NFL in pepper plants with a consideration of the air and root low temperature.

Previous studies showed that NFR was closely associated with FY in LT [13,39] and that NFR and fruit setting were key determinants to select LT-tolerant tomatoes and peppers with high fruit yields $[16,40]$. In line with a previous study, the effect of LT on NFR and FY resulted in the drastic decrease compared to those in CT (Figure 2B,C), suggesting that NFR and FY were closely correlated in LT. Moreover, LT affected the reduction in FD, FL, and NSF (Figure 3), resulting in irregular fruit shapes (Figure 5B). These findings were concordant with previous effects of LT on the flower morphology and the fruit development [18]. The studies assessed that the impact of LT on anther and ovary shapes caused the malformation of floral organs including the stunted stamen, the decreased number of pollen, and a reduced pollen activity by hindering pollination and fertilization [18,22], which further led to the abnormal formations of fruit development, irregular fruit shapes, and parthenocarpic fruits, together with reduced NSF [18,41]. The previous studies determined that the malformation of fruit shapes in rice, mango, and pepper plants were produced by the swollen ovary and shortened style in LT [2,6,42,43], indicating that the development of floral organs with a stamen and an ovary was very sensitive to LT. Furthermore, the parthenocarpic fruits and the declined NSF were associated with the balance of plant hormones, including auxin, gibberillin, and cytokinin due to the lack of fertilization, but might not be a defect of pollination $[44,45]$. Next, our important endeavor was to dissect the involvement of the plant hormones and the anatomic structures of floral organs during the period of flower development under different low temperature regimes.

We utilized the correlation matrix to perform a PCA analysis determining the crucial factors with 10 variables of agronomical traits between LT and CT, and 5 traits (scores > 0.30) were loaded into the plot. The first two PCA explained $65.76 \%$ of the agronomical variables 
(Figure 4). The angle between the vectors of traits, including FFW, FD, and FL in PC1 and NFR in PC2 with FY, were less than around $80^{\circ}$, indicating that the positive correlations were exhibited in the variables which were in line with previously published statistics [16]. Our finding showed that FFW, FD, and FL were closely correlated in LT effect. Studies were not conducted on the effects of LT and the LTN condition on fruit shapes such FFW, FD, and FL. On the one hand, a study reported that the FFW was positively associated with FD and pericarp thickness, but not in FL [46,47] under normal conditions. Moreover, some studies determined that the quantative trait locus (QTL) governing FFW and FD was linked on the choromosome P12, indicating that the positive trends between FFW and FD could be described from our PCA result [48]. Additionally, studies assumed that the mechanism of fruit development factors, including FD, FL, and FFW, were most likely shared [31,32]. Notably, in our current study, the effect of LT on the parameters of fruit development uncovered that FL was highly correlated with FD. Given that one study mentioned that the FL was governed by between 3 and 10 pairs of genes and was most likely affected by environmental conditions [46], further studies should investigate the mechanistic role of how the fruit developmental factors are governed by the gene clusters.

As our previous publication mentioned [27-29], the decreased NFR of sweet pepper in LT was associated with FY, showing the close correlation between the traits. In line with our current results, the previous PCA analysis of tomato plants also exhibited a strong correlation with FY and NFR in LT effect [16], suggesting that the NFR plays an important role in determining the yield-related parameters such as fruit set and fruit yield in pepper plants for breeding programs when selecting LT-tolerant peppers. A biplot analysis was further conducted to understand the multivariate relationships with 39 pepper accessions containing 27 chili and 12 bell peppers accessions (Figure 4). The evaluated agronomical traits and correlation matrix were applied to the cluster analysis and classified into seven groups (Figure 5A). Our findings showed that group 1 to group 3 tended to have negative trends with regard to the vegetative and reproductive parameters, but some accessions still exhibited moderate high and low values for these parameters. On the one hand, group 4 to group 7 tended to have positive trends, mainly with the reproductive parameters and with one or two of the vegetative parameter(s). Our previous study determined, in the selection criteria for LT-tolerant tomatoes, that tomato plants displayed different vegetative or reproductive indexes depending on fruit types [16]. Given that the clusters grouped with the reproductive index still exhibited one or two vegetative parameters in some accessions, or vice versa in different clusters, it is probable that the screening of the pepper accessions tolerant to LT were also taken into consideration with a different selection index among pepper accessions in the greenhouse. On the basis of our clustering of 39 pepper accessions (Figure 5A), we selected two LT-sensitive two chili and bell pepper accessions (C01 and C02 in group 2, P01 and P02 in group 1) which showed the low values of the vegetative and reproductive indexes, respectively. Additionally, it was observed that two LT-tolerant chili and bell peppers (C23 in group 4 and C22 in group 5; P08 in group 6 and P09 in group 7) mainly showed a high value of the reproductive index, such as FY, FFW, FL, and FD. Intriguingly, the fruit shapes of LT-sensitive chili and bell pepper genotypes were much smaller than those in CT, whereas the the fruit shapes of LT-tolerant genotypes were almost similar, or smaller to some exent, in comparison with those in CT (Figure 5B). Our results indicated that FL and FD played a crucial role in selecting LT-tolerant cultivars. Taken together, we assume that the results from our PCs and cluster analysis can be importantly considered as a measure for the selection of LT-tolerant pepper cultivars with reproductive and fruit shape-related traits, although the left traits are shown to have a minimal contribution to positive or negative directions. The selected accessions could be further used for pepper breeding programs to develop LT-tolerant chili and bell pepper cultivars with the selection criteria in winter greenhouses. 
Supplementary Materials: The following are available online at https://www.mdpi.com/article/10 .3390/agronomy11101986/s1, Figure S1: Air temperature was measured in LT and CT greenhouse during the period of pepper growth and development, respectively. Figure S2: The correlations coefficients between vegetative and reproductive traits in total population of pepper between LT and CT, Table S1: The information of chili and bell pepper accessions for evaluating agronomical traits under night low temperature in winter 2020-2021. Table S2: Loading matrix associated with the principal components analysis (PCA) for 10 agronomical traits.

Author Contributions: Conceptualization, M.-C.C. and E.-Y.Y.; methodology, S.N.R., M.-C.C., C.W.N. and E.-Y.Y.; investigation, S.N.R., K.L., H.-B.J. and E.-Y.Y.; writing-original draft preparation, S.N.R. and K.L.; writing-review and editing, S.N.R., K.L., E.-Y.Y. and M.-C.C.; visualization, S.N.R. and K.L.; supervision, M.-C.C. All authors have read and agreed to the published version of the manuscript.

Funding: This study was supported by a grant (Project No: PJ01267102 “Study on the physiological mechanism of temperature adaptable pepper lines") from the National Institute of Horticultural and Herbal Science, Rural Development Administration.

Institutional Review Board Statement: Not applicable.

Informed Consent Statement: Not applicable.

Data Availability Statement: The datasets presented in this study are available upon request to the corresponding author.

Conflicts of Interest: The authors declare no conflict of interest.

\section{References}

1. Kothari, S.; Joshi, A.; Kachhwaha, S.; Ochoa-Alejo, N. Chilli peppers-A review on tissue culture and transgenesis. Biotechnol. Adv. 2010, 28, 35-48. [CrossRef]

2. Bhutia, K.; Khanna, V.; Meetei, T.; Bhutia, N. Effects of climate change on growth and development of chilli. Agrotechnology 2018, 7, 2. [CrossRef]

3. Prohens, J.; Nuez, F. Handbook of Plant Breeding. Vegetables II: Fabaceae, Liliaceae, Solanaceae and Umbelliferae; Springer: New York, NY, USA, 2008; Volume 3, pp. 30-40.

4. Sun, T.; Xu, Z.; Wu, C.T.; Janes, M.; Prinyawiwatkul, W.; No, H. Antioxidant activities of different colored sweet bell peppers (Capsicum annuum L.). J. Food Sci. 2007, 72, 98-102. [CrossRef]

5. Sarada, C.; Ratnam, M.; Naidu, L.; Ramana, C.; Rajani, A.; Vijaya, T. Chilli production and productivity in relation to Seasonal weather conditions in Guntur District of Andhra Pradesh. Int. J. Pure Appl. Biosci. 2015, 3, 207-213.

6. Cruz-Huerta, N.; Williamson, J.G.; Darnell, R.L. Low night temperature increases ovary size in sweet pepper cultivars. HortScience 2011, 46, 396-401. [CrossRef]

7. Toki, T.; Ogiwara, S.; Aoki, H. Effect of varying night temperature on the growth and yields in cucumber. Acta Hortic. 1978, 87, 233-238. [CrossRef]

8. Horie, T.; de Wit, C.T.; Goudriaan, J.; Bensink, J. A formal template for the development of cucumber in its vegetative stage (I, II and III). In Proceedings of the Koninklijke Nederlandse Akademie Van Wetenschappen. Serie C: Biological and Medical Sciences; Wageningen University: Wageningen, The Netherlands, 1979; Volume 82, pp. 433-479.

9. Nilwik, H. Growth analysis of sweet pepper (Capsicum annuum L.) 1. The influence of irradiance and temperature under glasshouse conditions in winter. Ann. Bot. 1981, 48, 129-136. [CrossRef]

10. Ji, L.; Li, P.; Su, Z.; Li, M.; Guo, S. Cold-tolerant introgression line construction and low-temperature stress response analysis for bell pepper. Plant Signal. Behav. 2020, 15, 1773097. [CrossRef] [PubMed]

11. Foolad, M.; Lin, G. Relationship between cold tolerance during seed germination and vegetative growth in tomato: Germplasm evaluation. J. Am. Soc. Hortic. Sci. 2000, 125, 679-683. [CrossRef]

12. O'SULLIVAN, J.; Bouw, W. Pepper seed treatment for low-temperature germination. Can. J. Plant Sci. 1984, 64, 387-393. [CrossRef]

13. Seo, J.-U.; Hwang, J.-M.; Oh, S.-M. Effects of night temperature treatment of raising seedlings before transplanting on growth and development of pepper. J. Bio-Env. Con. 2006, 15, 149-155.

14. Bhatt, R.; Srinivasa Rao, N. Response of bell-pepper (Capsicum annuum) photosynthesis, growth, and flower and fruit setting to night temperature. Photosynthetica 1994, 28, 127-132.

15. Sherzod, R.; Yang, E.Y.; Cho, M.C.; Chae, S.Y.; Kim, J.H.; Nam, C.W.; Chae, W.B. Traits affecting low temperature tolerance in tomato and its application to breeding program. Plant Breed. Biotechnol. 2019, 7, 350-359. [CrossRef]

16. Rajametov, S.N.; Lee, K.; Jeong, H.-B.; Cho, M.-C.; Nam, C.-W.; Yang, E.-Y. Physiological Traits of Thirty-Five Tomato Accessions in Response to Low Temperature. Agriculture 2021, 11, 792. [CrossRef]

17. Oh, S.-Y.; Koh, S.C. Fruit Development and Quality of Hot Pepper (Capsicum annuum L.) under Various Temperature Regimes. Hortic. Sci. Technol. 2019, 37, 313-321. 
18. Mercado, J.; Mar Trigo, M.; Reid, M.; Valpuesta, V.; Quesada, M. Effects of low temperature on pepper pollen morphology and fertility: Evidence of cold induced exine alterations. J. Hortic. Sci. 1997, 72, 317-326. [CrossRef]

19. Pressman, E.; Moshkovitch, H.; Rosenfeld, K.; Shaked, R.; Gamliel, B.; Aloni, B. Influence of low night temperatures on sweet pepper flower quality and the effect of repeated pollinations, with viable pollen, on fruit setting. J. Hortic. Sci. Biotechnol. 1998, 73, 131-136. [CrossRef]

20. Shaked, R.; Rosenfeld, K.; Pressman, E. The effect of low night temperatures on carbohydrates metabolism in developing pollen grains of pepper in relation to their number and functioning. Sci. Hortic. 2004, 102, 29-36. [CrossRef]

21. Kato, K. Flowering and fertility of forced green peppers at lower temperatures. J. Jpn. Soc. Hortic. Sci. 1989, 58, 113-121. [CrossRef]

22. Rylski, I. Effect of night temperature on shape and size of sweet pepper (Capsicum annuum L.). Amer. Soc. Hort. Sci. J. 1973, 98, 149-152.

23. Aloni, B.; Pressman, E.; Karni, L. The effect of fruit load, defoliation and night temperature on the morphology of pepper flowers and on fruit shape. Ann. Bot. 1999, 83, 529-534. [CrossRef]

24. De Koning, A. The effect of different day/night temperature regimes on growth, development and yield of glasshouse tomatoes. J. Hortic. Sci. 1988, 63, 465-471. [CrossRef]

25. Rural Development Administration (RDA). Data Book of Agricultural Products Income for the Improvement of Agricultural Management in 2019; Rural Development Administration: Jeonju, Korea, 2020.

26. Elings, A.; Kempkes, F.; Kaarsemaker, R.; Ruijs, M.; Van De Braak, N.; Dueck, T. The Energy Balance and Energy-Saving Measures in Greenhouse Tomato Cultivation. Acta Hortic. 2005, 691, 67-74. [CrossRef]

27. Rylski, I.; Spigelman, M. Effects of different diurnal temperature combinations on fruit set of sweet pepper. Sci. Hortic. 1982, 17, 101-106. [CrossRef]

28. Rylski, I. Investigations on the Influence of Suboptimal Temperatures on the Flowering, Fruit Setting and Development of Sweet Pepper (Capsicum annum L.). Ph. D. Thesis, Hebrew University of Jerusalem, Jerusalem, Israel, 1971; pp. 1-96.

29. Rylski, E.; Kempler, H. Fruit set of sweet pepper (Capsicum annuum L.) under plastic covers. HortScience 1972, 7, $422-423$.

30. Wang, C. Alleviation of chilling injury in tropical and subtropical fruits. In III International Symposium on Tropical and Subtropical Fruits; International Society for Horticultural Science: Bierbeek, Belgium, 2004; Volume 864, pp. 267-273.

31. Barchi, L.; Lefebvre, V.; Sage-Palloix, A.-M.; Lanteri, S.; Palloix, A. QTL analysis of plant development and fruit traits in pepper and performance of selective phenotyping. Theor. Appl. Genet. 2009, 118, 1157-1171. [CrossRef] [PubMed]

32. Yarnes, S.C.; Ashrafi, H.; Reyes-Chin-Wo, S.; Hill, T.A.; Stoffel, K.M.; Van Deynze, A. Identification of QTLs for capsaicinoids, fruit quality, and plant architecture-related traits in an interspecific Capsicum RIL population. Genome 2013, 56, 61-74. [CrossRef] [PubMed]

33. Yang, S.; Tang, X.-F.; Ma, N.-N.; Wang, L.-Y.; Meng, Q.-W. Heterology expression of the sweet pepper CBF3 gene confers elevated tolerance to chilling stress in transgenic tobacco. J. Plant Physiol. 2011, 168, 1804-1812. [CrossRef] [PubMed]

34. Hou, X.-M.; Zhang, H.-F.; Liu, S.-Y.; Wang, X.-K.; Zhang, Y.-M.; Meng, Y.-C.; Luo, D.; Chen, R.-G. The NAC transcription factor CaNAC064 is a regulator of cold stress tolerance in peppers. Plant Sci. 2020, 291, 110346. [CrossRef]

35. Kong, X.-M.; Zhou, Q.; Zhou, X.; Wei, B.-D.; Ji, S.-J. Transcription factor CaNAC1 regulates low-temperature-induced phospholipid degradation in green bell pepper. J. Exp. Bot. 2020, 71, 1078-1091. [CrossRef]

36. Chinnusamy, V.; Zhu, J.-K.; Sunkar, R. Gene Regulation During Cold Stress Acclimation in Plants. Methods Mol. Biol. 2010, 639, 39-55. [PubMed]

37. Bakker, J.; Van Uffelen, J. The effects of diurnal temperature regimes on growth and yield of glasshouse sweet pepper. Neth. J. Agri. Sci. 1988, 36, 201-208.

38. Ohtaka, K.; Yoshida, A.; Kakei, Y.; Fukui, K.; Kojima, M.; Takebayashi, Y.; Yano, K.; Imanishi, S.; Sakakibara, H. Difference Between Day and Night Temperatures Affects Stem Elongation in Tomato (Solanum lycopersicum) Seedlings via Regulation of Gibberellin and Auxin Synthesis. Front. Plant Sci. 2020, 11, 1947. [CrossRef] [PubMed]

39. Phatak, S. Top and root temperature effects on tomato flowering. J. Am. Soc. Hortic. Sci. 1966, 88, 527-531.

40. Goodstal, F.J.; Kohler, G.R.; Randall, L.B.; Bloom, A.J.; Clair, D.A.S. A major QTL introgressed from wild Lycopersicon hirsutum confers chilling tolerance to cultivated tomato (Lycopersicon esculentum). Theor. Appl. Genet. 2005, 111, 898-905. [CrossRef]

41. Patterson, B.D.; Reid, M.S. Genetic and environmental influences on the expression of chilling injury. In Chilling Injury of Horticultural Crops; CRC Press: Boca Raton, FL, USA, 1990; pp. 87-112.

42. Issarakraisila, M.; Considine, J. Effects of temperature on pollen viability in mango cv. 'Kensington'. Ann. Bot. 1994, 73, 231-240. [CrossRef]

43. Satake, T.; Hayase, H. Male sterility caused by cooling treatment at the young microspore stage in rice plants: V. Estimations of pollen developmental stage and the most sensitive stage to coolness. Jpn. J. Crop Sci. 1970, 39, 468-473. [CrossRef]

44. Polowick, P.; Sawhney, V. Temperature effects on male fertility and flower and fruit development in Capsicum annuum L. Sci. Hortic. 1985, 25, 117-127. [CrossRef]

45. Sawhney, V.K.; Shukla, A. Male sterility in flowering plants: Are plant growth substances involved? Am. J. Bot. 1994, 81, 1640-1647. [CrossRef]

46. Zhigila, D.A.; AbdulRahaman, A.A.; Kolawole, O.S.; Oladele, F.A. Fruit morphology as taxonomic features in five varieties of Capsicum annuum L. Solanaceae. J. Bot. 2014, 2014, 1-6. [CrossRef] 
47. Paran, I.; Van Der Knaap, E. Genetic and molecular regulation of fruit and plant domestication traits in tomato and pepper. J. Exp. Bot. 2007, 58, 3841-3852. [CrossRef] [PubMed]

48. Vilarinho, L.B.O.; da Silva, D.J.H.; Greene, A.; Salazar, K.D.; Alves, C.; Eveleth, M.; Nichols, B.; Tehseen, S.; Khoury, J.K.; Johnson, J.V. Inheritance of fruit traits in Capsicum annuum: Heirloom cultivars as sources of quality parameters relating to pericarp shape, color, thickness, and total soluble solids. J. Am. Soc. Hortic. Sci. 2015, 140, 597-604. [CrossRef] 